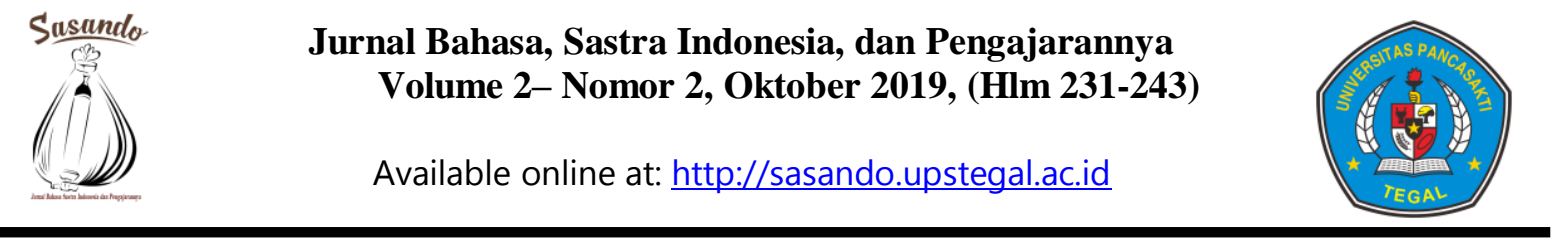

\title{
NILAI KEARIFAN LOKAL FOLKLOR MASYARAKAT KABUPATEN BINTAN
}

\author{
Suhardi ${ }^{1}$ \\ Tessa Dwi Leonny ${ }^{2}$ \\ Elfa Oprasmani ${ }^{3}$
}

Program Studi Pendidikan Bahasa dan Sastra FKIP UMRAH

Jl. Politeknik Senggarang Tanjungpinang Indonesia

E-mail: suhardi@umrah.ac.id, tessadwileoni@gmail.com, elfaoprasmani@umrah.ac.id

\begin{abstract}
ABSTRAK
Masyarakat kabupaten Bintan sudah sejak lama dikenal memiliki berbagai jenis folklore (Melayu). Namun, belum banyak diangkat sebagai objek penelitian, khususnya dari aspek nilai kearifan lokalnya. Metode penelitian yang digunakan adalah metode deskriptif kualitatif. Teknik pengumpulan data menggunakan teknik wawancara dan dokumen. Analisis data dilakukan dengan cara analisis isi. Hasil penelitian yang diperoleh adalah folklore masyarakat kabupaten Bintan mengandung nilainilai kearifan lokal, seperti: (1) nilai Islami, (2) nilai budi-pekerti, (3) nilai social, (4) nilai kerja keras, dan (5) nilai pendidikan.
\end{abstract}

\section{Kata Kunci: Nilai, Kearifan Lokal, Folklore}

\section{ABSTRACT}

Bintan Regency community has long been known to have various folklore geniuses. But not many have been appointed as objects of research, particularly in terms of the value of their local wisdom. This study used descriptive qualitatative method. Data collection using interview teachniques and documents. Data analysis uses content analysis techniques. The result obtained showed that folklore district of Bintan community contained local wisdom values such as the value of Islamics religion, moral value, social values, hard work values, and educational values.

Keywors: velue, local wisdom, folklore 


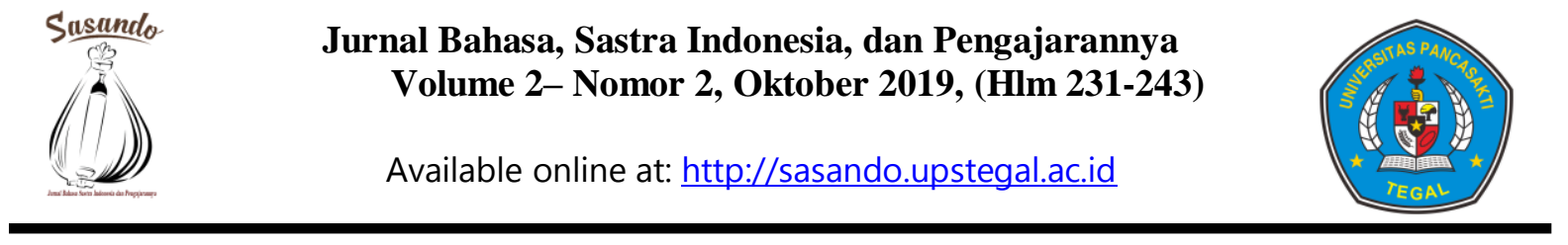

\section{PENDAHULUAN}

Seiring kuatnya arus budaya asing masuk ke Indonesia, banyak sedikitnya juga berdampak kepada prilaku masyarakat, khususnya generasi muda. Pertama, ada gejala perubahan prilaku di kalangan generasi muda yang lebih menganggap budaya asing itu lebih baik kerimbang budaya bangsanya sendiri. Kedua, ada gejala yang terlihat di kalangan generasi muda terhadap minat dan rasa cintanya yang semakin rendah terhadap budaya bangsanya sendiri sehingga motivasi dan kepedulian mereka terhadap pelestarian dan pengembangan budayanya semakin rendah. Bahkan mereka mulai ikut-ikutan melestarikan budaya asing tersebut. Lihat saja dari cara mereka berpakaian yang sudah tidak mencerminkan lagi budaya Indonesia. Cela Jean sudah menjadi trent di kalangan generasi muda laki-laki ketimbang menggunakan pakaian Melayu. Budaya malu sudah mulai hilang di kalangan generasi muda kita, lihat saja pakaian mereka saat keluar rumah. Celana pendek dulunya hanya digunakan untuk di rumah saja kini telah digunakan keluar rumah (supermarket). Celana dan baju berlubang (robek) sudah menjadi gaya, sementara dulu orang malu menggunakan keluar rumah. Pakaian ketat, dulu malu orang menggunakan keluar rumah tetapi kini sudah menjadi gaya. Mempertontonkan aurat dianggap model bukan dosa. Kegiatan bergunjing saat ini menjadi suatu acara favorit di berbagai media televisi, pada hal perbuatan itu jelas-jelas adalah dosa.

Pertunjukan seni budaya asli Indonesia saat ini sudah mulai sepi penontonnya ketimbang petunjukan seni budaya asing. Ada sikap yang keliru yang saat ini ada di dalam diri generasi muda kita, yaitu kegiatan seni budaya asli dianggap kuno, tak menarik, dan tak berguna.
Mewariskan seni budaya asli nenek moyang kita dianggap tak penting dan sia-sia ketimbang mewariskan budaya asing. Film asing lebih disukai ketimbang film Indonesia.

Kondisi tersebut juga didukung oleh media elektronik yang ada saat ini. Mereka lebih suka menayangkan seni budaya asing ketimbang seni budaya yang asli Indonesia. Pentas seni budaya asing lebih ramai penontonnya ketimbang pentas seni budaya asli bangsa Indonesia. Karya sastra asing lebih hidup dan berkembang ketimbang ketimbang karya sastra milik bangsa Indonesia. Bentuk-bentuk folklore asing lebih banyak diketahui generasi muda kita sat ini ketimbang bentuk-bentuk folklore yang ada di Indoesia. Inilah potret suram eksistensi budaya asli Indonesia saat ini. Ancaman yang menakutkan tersebut hendaknya perlu menjadi perhatian semua pihak. Sudah saatnya para tokoh elit kita memikirkan kebudayaan pelestarian dan pengembangan kebudayaan bangsanya ke depan. Haruskah kita membiarkan budaya kita semakin terpuruk dan punah. Apalagi yang akan menjadi identitas kita sebagai bangsa Indonesia. Usaha jeput bola berbagai kalangan peneliti dari berbagai Perguruan Tinggi tentunya sangat diharapkan. Tak terkecuali tentunya UMRAH, khususnya dosen-dosen di Jurusan Pendidikan Bahasa dan Sastra Indonesia. Melalui kegiatan Tri Dharma Perguruan Tingginya diharapkan memiliki perhatian tinggi terhadap pelestarian dan pengembangan budaya yang ada (budaya Melayu) diantaranya adalah bidang ilmu folklore.

Masyarakat kabupaten Bintan sudah sejak lama memiliki nilai-nilai kearifan lokal berupa bentuk-bentuk folklor. Namun, proses pewarisannya kepada generasi muda tidak berjalan sebagaimana yang diharapkan. Baik pewarisan dalam bentuk 
lisan maupun tulisan. Hal ini sebagaimana terlihat, sewaktu kita tanyakan kepada gene- rasi mudanya berkaitan dengan bentuk- bentuk folklore apa saja yang mereka keta- hui. Rata-rata mereka tidak banyak menge- tahuinya. Dengan kondisi seperti ini diyakini ada beberapa bentuk folklor masyarakat Kabupaten Bintan saat ini telah hilang dalam kehidupan soaial masyarakat seiring penutur aslinya yang sudah tiada (wafat). Oleh sebab itulah, diperlukan sebuah usaha atau tin- dakan penyelamatan yang cepat agar folk- lore yang ada sebagai kearifan lokal tidak punah (hilang). Usaha tersebut tentunya mulai dari pendokumentasian tertulisnya dan penggalian nilai-nilai kearifan lokal yang terkandung di dalamnya. Selanjutnya adalah memperkenalkan ke kalangan generasi muda melalui kegiatan pembelajaran di kelas.

Mengingat bentuk-bentuk folklore yang ada dalam masyarakat Bintan begitu banyak, maka pada kesempatan ini peneliti hanya mengangkat legenda saja, yaitu: legenda Putra Lokan dan legenda Putri Pandan Berduri. Tujuan penelitian ini adalah mendeskripsikan nilai-nilai kearifan lokal legenda Putra Lokan dan (b) untuk mendeskripsikan nilai-nilai kearifan lokal yang terkandung dalam legenda Putri Pandan Berduri.

Kata folklore berasal dari bahasa Inggris, yaitu "folklore". Secara etimologi, kata folklore berasal dari 2 kata, yaitu dari kata 'folk' dan 'lore'. Kata Folk bermakna kolektif dan lore bermakna tradisi. Folklore adalah sekelompok orang yang telah memiliki ciri-ciri pengenal fisik, sosial, dan kebudayaan sehingga dapat dibedakan dari kelompok lainnya. Folklore juga dapat didefinisikan sebagai kebudayaan kolektif, yang tersebar dan diwariskan secara turun- temurun, baik dalam bentuk lisan, gerak isyarat, maupun alat bantu pengingat (Danandjaja dalam Pudentia, 1998:5

James Danandjaja dalam Pudentia (1998:54) menyatakan bahwa folklor mempunyai tiga bentuk besar, yaitu: (1) folklor lisan, (2) folklor bukan lisan, dan (3) folklor sebagian lisan. Folklor Lisan adalah folklor yang bentuknya memang murni lisan. Yang termasuk ke dalam kelompok ini adalah: a) bahasa rakyat, seperti: logat, julukan, dan sebagainyal; b) ungkapan tradisional, seperti: peribahasa, pepatah, pemeo; c) pertanyaan tradisional, seperti: teka-teki; d) puisi rakyat, seperti: pantun, gurindam, syair; e) cerita prosa, seperti: mite, legende, dongeng; dan f) nyanyian rakyat. Folklor Bukan Lisan adalah folklor yang bentuknya bukan lisan, walaupun cara pembuatannya diajarkan secara lisan. Kelompok ini dibagi menjadi dua, ialah a) material, seperti: arsitek rakyat, kerajinan tangan, pakaian, perhiasan, masakan, minumam, obat tradisi; dan b) Bukan Material, seperti: musik rakyat, gerak isyarat tradisional, bunyi isyarat komunikasi rakyat, dan sebagainya. Folklor Sebagian Lisan adalah folklor yang bentuknya merupakan campuran unsur lisan dan bukan lisan, misalnya: kepercayaan rakyat, permainan rakyat, teater, tarian, adat-istiadat, upacara, pesta, batu permata, dan sebagainya.

Ada beberapa definisi berkaitan dengan apa itu nilai dan apa itu kearifan lokal. Nilai adalah sifat-sifat penting dan berguna bagi manusia (Kemendikbudnas, 2011:356). Nilai adalah sesuatu yang berkaitan dengan harkat atau mutu sesuatu (Sugono, 2009:400). Dengan demikian dapat disimpulkan bahwa nilai adalah sesuatu yang berhubungan dengan harga, harkat, mutu, yang berguna bagi kehidupan manusia dalam bermasyarakat. 


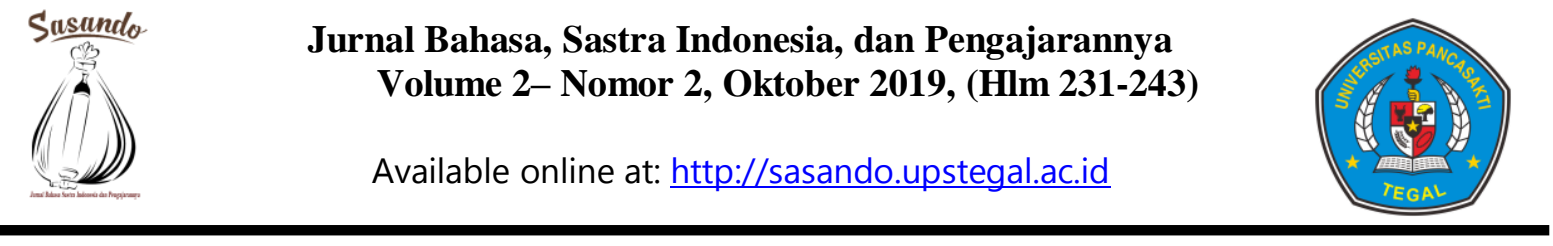

Kearifan lokal (local wisdom) menurut Ajip Rodisi (Nunung, 2016:238) adalah kemampuan kebudayaan setempat dalam menghadapi pengaruh kebudayaan asing sewaktu kedua kebudayaan itu berhubungan. Selanjutnya nana Supriatna (Nunung, 2016:239) menyatakan pemikiran, kesadaran, tindakan, keyakinan yang teruji yang dipraktikkan oleh masyarakat secara turun temurun dan menjadi landasan/ pdoman mereka dalam menjalankan kehi- dupannya. Dari sumber di atas dapat disimpulkan nilai kearifan lokal adalah harkat yang berkaitan dengan pemikiran, kesadaran, tindakan, keyakinan yang teruji yang dipraktikkan oleh masyarakat secara turun temurun dan menjadi lan-dasan/ pedoman mereka dalam menjalankan kehi- dupannya.

Masyarakat kabupaten Bintan merupakan masyarakat Melayu yang sebagian aktivitas kehidupan sehari-harinya sangat menjunjung tinggi nilai-nilai budaya Melayu. Nilai-nilai tersebut sebagaimana tertuang dalam 12 pasal yang ada dalam Gurindam Dua Belas karya Raja Ali Haji. Nilai-nilai tersebut meliputi: (a) nilai agama (Islam), (b) budi - pekerti, (3) sosial, (4)kerja keras, dan (5) nilai pendidikan. Keli- ma nilai tersebut dapat dikatakan sebagai nilai kearifan lokal masyarakat Melayu, tak terkecuali masyarakat Kabupaten Bintan. Kelima nilai yang tertuang dalam Gurindam Dua Belas tersebut telah menjadi sumber kajian dan pedoman (tunjuk-ajar) dalam hidup bermasyarakatnya.

\section{METOD PENELITIAN Jenis Penelitian}

Penelitian ini berjeniskan penelitian kualitatif. Penelitian yang lebih menekankan dari aspek deskripsi atau gambaran dari objek yang diamati. Penelitian dilakukan untuk memahami dan menjelaskan fenomena yang telah berjalandan sedang berjalan (Iskandar, 2008:186).

\section{Waktu Penelitian}

Adapun yang dimaksud dengan waktu penelitian di sini adalah waktu kegiatan penelitian ini dilaksanakan. Penelitia ini dilaksanakan dari Maret 2019-Oktober 2019.

\section{Subjek Penelitian}

Target atau subjek penelitian ini adalah legenda Putra Lokan dan Leegnda putrid Pandan Berduri yang terdapat dalam masyarakat kabupaten Bintan Tanjungpinang .

\section{Prosedur Penelitian}

\section{(1) Metode Penelitian}

Penelitian ini menggunakan metode deskriptif kualitatif, yaitu mendeskripsikan isi yang terkandung dalam folklore yang menjadi objek pengamatan.

\section{(2) Teknik Pengumpulan Data}

Data dikumpulkan dengan menggunakan teknik (1) wawancara dan (2) dokumen. Wawancara dilakukan dengan mewawancarai nara sumber berkaitan dengan bentuk-bentuk folklore yang ada dalam masyarakat kabupaten Bintan. Doku- men diperlukan jika peneliti merasa data yang diperoleh belum lengkap. Dengan demikian peneliti berusaha mencarinya dokumen pendudukungnya.

\section{(3) Teknik Analisis Data}

Analisis data dilakukan dengan menggunakan teknik analisis isi (content analysis), yaitu analisis isi nilai-nilai kearifan lokal yang terkandung dalam 
legenda Putra Lokan dan legenda putrid Pandan Berduri. Pada dasarnya analisis konten dalam bidang sastra tergolong upaya pemahaman karya sastra dari aspek intrinsik. Aspek-aspek yang melingkupi di luar estetika struktur sastra, dibedah, dihayati, dan dibahas secara mendalam, seperti: nilai moral, pendidikan, filosofis,, relegius, mau- pun kesejarahannya (Endraswara, 2011: 160).

\section{HASIL DAN PEMBAHASAN Hasil}

a. Legenda Putra

Lokan Sinopsis

Tersebutlah di daerah hulu sungai Bintan, tinggallah seorang raja. Raja tersebut memerintah sangatlah adil sehingga sangat disenangi rakyatnya. Raja tersebut mempunyai seorang permaisuri yang cantik jelita, akan tetapi selama perkawinannya dengan sang Raja, ia belum dikaruniai seorang anak. Hidup mereka terasa sepi. Mereka ingin sekali memiliki anak untuk mengiasi kehidupan rumah tangga mereka. Suatu ketika raja mengajak permaisurinya berjalan menyusuri Sungai Bintan. Tiba-tiba saja permaisuri raja jatuh pingsan tak diketahui entah apa penyebabnya. Raja saat itu tentu saja sangat cemas karena tadinya permaisuri sehatsehat saja. Permaisuri berangkat dari istana tak terlihat gejala yang mencurigakan. Mengapa tiba-tiba saja per- maisuri pingsan. Sang Raja sangatlah heran. Dipanggillah tabib yang sangat terkenal untuk mengobati sang Permaisuri Raja. Tabib berusaha mediagnosis penyakit permaisuri melalui ilmu kebatinannya.

Dibacakanlah mantra-mantra oleh sang tabib sambil berkomat-kamit. Hasilnya, sang tabib tidak dapat mengetahui penyakit yang sedang diderita permaisuri raja. Sang tabib kemudian menyampaikan kepada sang Raja bahwa permaisuri tidak ada sakit apaapa. Adapun penyebab sang permaisuri pingsan adalah karena sang permaisuri sedang berbadan dua alias hamil. Sang permaisuri tidak kuat untuk melakukan perjalan jauh. Mendengar perkataan sang tabib, raja sangatlah gembira sebab istrinya kini sedang mengandung anaknya. Hatinya sangat bahagia sebab sudah lama dirinya mendambakan seorang anak sebagai pewaris kerajaannya kelak. Mendengar istri raja telah hamil, rakyat menyambutnya dengan suka cita, sebentar lagi rajanya memiliki seorag anak. Setelah sembilan bulan sepuluh hari lamanya permaisuri mengandung, kini tibalah masa-masa sang permaisuri melahirkan. Sang Raja bersama perangkat istana lainnya bersiap-siap menyambut kelahiran jabang bayinya. Namun, suasana yang awalnya ceria berubah seketika menjadi kecewa. Sang permaisuri ternyata bukan melahirkan seorang bayi melainkan seekor lokan. Atas realitas yang terjadi tersebut, sang Rajamerasa kecewa dan malu. Sang Raja bingung apatindakan yang harus dilakukan. Di saat sang Raja sedang bingung, tiba-tiba datanglah seorang Ben- dahara Kerajaan.

Sang Bendahara menyarankan agar sang Raja pecepatnya membuang sang permaisuri dan anaknya ke hutan sebab bila tidak makadunia kerajaan akan gempar, sang Raja beranakan seekor lokan. Raja akan malu atas peristiwa ini. Saran yang disampaikan sang Bendahara kerajaan ter- nyata diterima langsung saja oleh sang Raja tanpa pikir panjang. Pada hal, di balik saran yang diberikan sang Bendara itu terselip niat jahat agar dirinya kelak lebih mudah melakukan kudeta kepada sang Raja dan mengambil alih tampuk kepemimpinan kerajaan. Sang Bendahara bersama para pengawalnya 


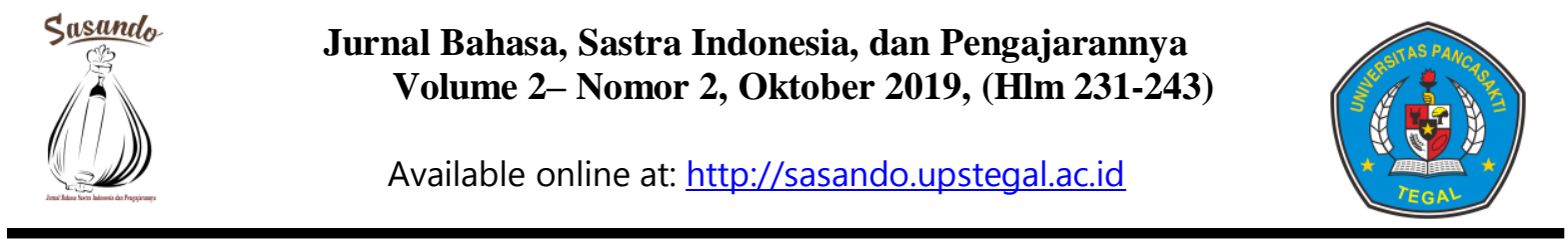

membawa permaisuri bersama anaknya ke hutan. Setibanya di tengah hutan, sang permairuri bersama anaknya ditinggal sang Bendara begitu saja. Tentu saja, sang permaisuri menjadi bingung dan karena hari mulai memasuki senja sang permaisuri mulai timbul rasa takutnya.

Dirinya tidak tahu mau pergi kemana sebab dirinya tidak mengenal lokasi hutan tersebut. Pada saat sang permaisuri merasa takut itulah, sang permaisuri coba meman- jatkan doa kepada Allah agar diri dan anaknya dapat diselamatkan dari berbagai ganguan jin dan setan penghuni hutan. Doa sang permaisuri ternyata dikabulkan Allah. Tiba-tiba sambil terbongkok-bongkok keluar seorang nenekdari dalam hutan.Nenek itu bernama Nenek Kebayan. Nenek Kebayan menanyakan maksud dan tujuan sang permaisuri bersama anaknya masuk hutan ini. Sang permaisuri menjawab bahwa dirinya ditinggalkan oleh sang Bendahara bersama anaknya di tengah hutan ini. Ia tak tahu mau pergi kemana. Atas penjelasan tersebut, sang Nenek Kebayan kasihan dan mengajak untuk tinggal saja bersamanya. Sang permaisuri menerima tawaran Nenek Kebayan tersebut. Rumah nenek Kebayan hanyalah sebuah gubuk kecil di tengah hutan.

Setelah 18 tahun sang permaisuri dan anaknya tinggal di tengah hutan bersama Nenek Kebayan, lokan anak permaisuri bertambah besar. Malam itu adalah malam bulan purnama, tiba-tiba dari dalam kolam tempat anak permaisuri dibesarkan, muncul seorang pemuda yang sangat tampan dan ikdaya.Pemuda itu mengaku bahwa dirinya adalah lokan yang di dalam kolam selama ini, putra sang permaisuri yang dibuang sang Raja di tengah hutan. Mendengar penjelasan sang pangeran tersebut, permaisuri sangatlah gembira hatinya. Sang Pangeran bertambah besar juga dan akhirnya sang permaisuri pamit dengan sang Nenek Kebayan bahwa dirinya sudah rindu nak berjumpa dengan suami (sang Raja).

Nenek Kebayan hanya bisa mengiyakan saja. Namun sebelum berangkat sang Pangeran bersama sang permaisuri (ibu pangeran) menyusun strategi untuk mengamati kondisi istana saat ini, selama dirinya hidup bersama ibunya di hutan. Putra Lokan dan ibunya berangkat menuju istana. Putra Lokan dan ibunya tinggal di pinggiran kota dekat lingkungan istana. Agar bisa bebas mengamati kondisi istana, Putra Lokan menyamar menjadi seorang pedagang keliling. Dari hasil penyamaran tersebut, diketahui bahwa ternyata sekarang sang Raja tidak memerintah lagi. Ia ditawan oleh bendahara yang jahat itu di sebuah sumur beracun. Putra Lokan menyampaikan hal tersebut kepada ibunya. Mereka pun lalu merancang strategi untuk melakukan penyerangan terhadap Bendahara Kerajaan. Putra Lokan dan ibunya menyerang bendahara kerajaan yang busuk hati dan jahat tersebut. Berkat kegigihannya, Putra Lokan dan ibunya berhasil melumpuhkan para pengawal istana dan membebaskan sang Raja dari sumur beracun. Sang Raja tidak tahu siapa pemuda tampan yang telah membebaskannya itu. Begitu juga sang Raja tidak tahu bahwa wanita yang bersama pemuda tersebut adalah permaisuri yang telah dibuangnya kehutan. "Hai, Pangeran tampan, siapa gerangan dirimu yang telah menyelamatkan aku?'Sang pangeran hanya menjawab, "Aku bukan siapa-siapa. Biarlah nanti ibuku yang akan menjawab siapa diriku sebenarnya". Tak lama kemudian, datangnya ibu sang pangeran. Alahkah terkejutnya sang Raja, ternyata wanita itu adalah permaisurinya 


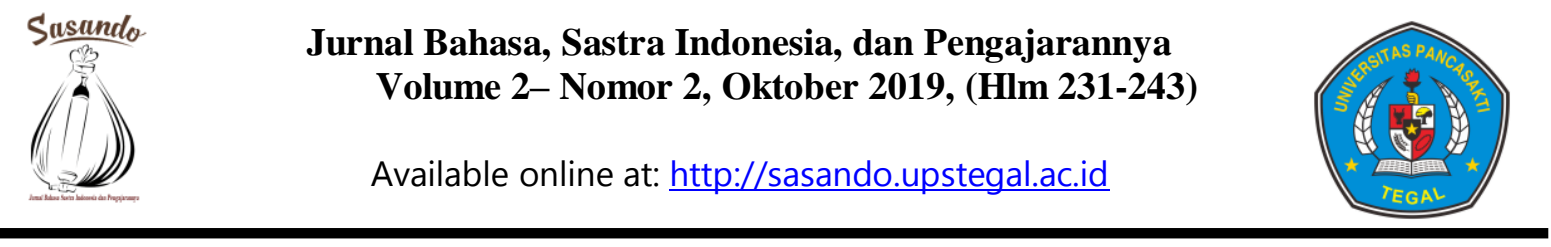

yang dulu dibuangnya ke hutan bersama anaknya. Akhirnya per- maisuri pun enjelaskan bahwa pemuda tampan yang telah membebaskannya itu adalah anaknya sendiri, lokan yang telah berubah menjadi pemuda tampan.

Alangkah bahagianya sang
Raja mendengar
penjelasan permaisurinya ter- sebut. Sang Raja sangat menyesal telah menelantarkan istri dan anaknya tersebut. Sang Raja meminta maaf atas kesalahannya selama ini. Permasuri dan Putra Lokan pun memaafkan kesalahan sang Raja. Mereka kembali hidup bersamadan bahagia.

www.butang-emas.net/.../14-cerita-r...melayu.html 30 mARET 2017, 16:30

\section{b. Legenda Putri Pandan}

Berduri Sinopsis

Legenda Putri Pandan Berduri mengandung alur maju. Peristiwa dimulai dari awal hingga akhir. Hal tersebut sebagaimana terlihat berikut ini.

Dulu kala, di daerah kabupaten Bintan terdapatlah masyarakat Suku Laut. Dalam kehidupan sosial-budayanya, masyarakat suku laut ini dipimpin seorang kepala suku bernama Batin Lagoi. Sebagai kepala suku yang bijak, Batin Lagoi selalu mem- perhatikan kehidupan rakyatnya. Setiap hari dirinya selalu menyempatkan diri untuk turun langsung ke masyarakatnya untuk mengetahui aktivitas sosial masyarakat sukunya. Dirinya tak mau hanya duduk di singgasana saja dan menerima laporan dari para pembantunya.

Hampir setiap sore atau petang, Batin Lagoi mengelilingi kampung hingga ke tepi pantai. Atas prilaku baik yang diperlihatkan Batin lagoi ini, masyarakat sukunya sangat senang. Masyarakat dapat hidup dengan rukun dan damai. Kehidupan pun dirasakan masyarakat sukunya semakin baik, selama kepemimpinannya.

Seperti biasanya, batin Lagoi sore itu mengilingi kampung hingga ke tepi pantai. Batin Lagoi memperhatikan semua aktifitas yang dilakukan masyarakat sukunya. Tak lama sampailah batin Lagoi di tepi pantai. Tak diduga dan disangka, Batin Lagoi mendengar sayup-sayup suara tangisan bayi. Batin Lagoi mencoba mencari sumber tangisan bayi itu. Setelah beberapa lama mencari sumber suara tangisan bayi tersebut, Batin Lagoi berhasil menemukannya. Suara bayi yang mengis, mungkin karena haus atau lapar yang ditidurkan di atas lembaran pandan berduri di sebuah semak di sudut pantai. Batin Lagoi sangat kasihan melihat bayi malang tersebut. Dirinya mengambil bayi tersebut dari tempatnya dan menggendong bayi tersebut ke rumahnya. Dirinya berniat untuk merawat bayi tersebut dan membe-sarkannya. Bahkan Batin Lagoi juga ingin mengangkat bayi tersebut sebagai anaknya sendiri.

Batin Lagoi mengumpulkan masyarakat sukunya untuk memberitahukan bahwa dirinya baru saja mendapatkan seorang bayi yang terlantar di semak pinggir laut. Batin Lagoi menanyakan apakah ada masyarakat yang kehilangan anak bayinya. Masyarakat suku laut pimpinannya ternyata mengatakan tidak ada yang kehilangan anaknya. Setelah memastikan hal tersebut, Batin Lagoi langsung mengumumkan bahwa sejak hari ini bayi ini resmi diangkat sebagai anaknya sendiri. Batin Lagoi menyatakan kepada masyarakatnya bahwa dirinya akan memelihara anak ini hingga dewasa kelak.

Batin Lagoi memberikan nama bayi yang diangkat sebagai anaknya sendiri tersebut dengan nama Putri Pandan Berduri. Nama ini tentunya sangat berkaitan dengan tempat si bayi awal mula ditemukan Batin 


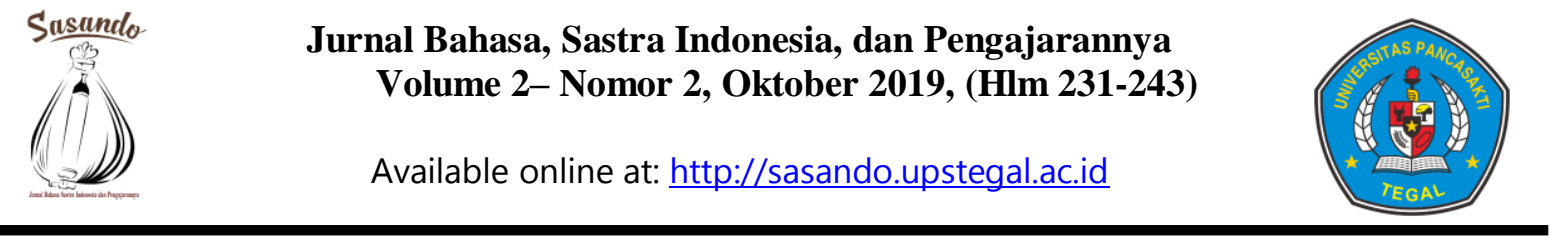

Lagoi, yaitu di atas pandan berduri.

Karena tidak memiliki anak perempuan, Batin Lagoi memelihara Putri dengan penuh kasih sayang dan perhatian. Tumbuhlah Putri menjadi anak perawan yang cantik, anggun, santun, dan bertutur kata yang baik. Hari demi hari, bulan demi bulan, dan tahun pun berganti. Kini Putri sudah menjadi gadis yang dewasa.

Melihat keanggunan dan kecantikan Putri, banyaklah para pemuda yang jatuh hati kepadanya. Melihat anaknya yang semakin dewasa, senanglah hati Batin Lagoi memandangnya. Tumbuhlah niat di dalam hati Batin Lagoi, kelak anak gadisnya ini mendapatkan jodoh lelaki tampan dan berketurunan raja. Batin Lagoi selalu berdoa semoga niatnya tersebut dikabulkan Tuhan.

Di daerah Galang memerintahlah seorang raja kecil yang berhasil membawa masyarakatnya hidup makmur. Raja kecil ini sangat peduli dengan masyarakatnya. Wajar saja bila atas kepemimpinannya itu, masya- rakat hidup rukun, damai, dan makmur. Namun, seiring usianya yang semakin lanjut, dirinya menyadari bahwa usianya tak lama lagi. Kepemimpinan kerajaan harus dilanjutkan oleh anakanaknya. Raja Galang ini akhirnya mengumpulkan anak-anaknya untuk menyampaikan hasrat hatinya. Raja Galang menyatakan bahwa pucuk pimpinan kerajaan akan diserahkan kepada Julela (anak tertua) sebagai pelanjut kepemimpinan karena dirinya tak mungkin lagi melanjutkan tahta kekuasaan mengingat dirinya yang sudah tua dan lemah.

Mendengar pernyataan ayahnya itu, sikap sombong yang ada dalam dirinya mulai muncul. Dirinya membayangkan jika kelak dirinya memegang tampuk kerajaan, semua perintah yang dikeluar-kannya harus dilaksanakan rakyatnya. Rakyat tak boleh membantahnya. Keangkuhan san kesombongan yang dimiliki Julela sangat terlihat di mata adiknya yang bernama Jenang Perkasa. Jenang sangat tidak suka dengan sikap buruk kakaknya tersebut. Namun dirinya tetap menahan diri sebab dirinya tak mau memusingkan kepala ayahnya. Dirinya tak mau membuat keributan. Jenang tak ingin ayahnya sakit akibat dirinya bertengkar dengan kakaknya tersebut.

Julela semakin hari semakin memperlihatkan sikap buruknya. Awalnya Jenang Perkasa hanya berusaha sabar dan diam diri saja. Namun lama kelamaan dirinya juga tak tahan diperlakukan tidak elok oleh sang kakak (Julela). Jenang Perkasa akhirnya memutuskan diri untuk meninggalkan rumah, meninggalkan ayah yang dicintainya. Jenang memohon doa restu dan izin kepada ayahnya. Dengan berat hati, sang ayah memberikan izin Jenang. Dengan berbekal sebuah pompong kecil, Jenang mencoba mengarungi lautan dengan tujuan yang belum jelas entah kemana. Dirinya terus mendayung pompong, mengikuti arah arus laut. Tak lama kemudian, Jenang melihat sebuah pulau dari kejauhan. Jenang menghampiri pulau tersebut serta menyandarkan pompongnya di pantai. Pulau tersebut bernama Pulau Bintan.

Jenang Perkasa di pulau Bintan bekerja sebagai pedagang. Masyarakat pulau Bintan tidak mengetahui bahwa Jenang merupakan anak seorang raja dari Pulau Galang. Jenang pun tak pernah mengabari kepada orangorang bahwa dirinya anak keturunan raja.

Kepintaran Jenang dalam berdagang membuahkan hasil, Jenang memperoleh keuntungan yang banyak. Hidup Jenang semakin baik. Jenangpun dalam bergaul dengan tetangga dan orang-orang sangat baik pula. Masyarakat akhirnya banyak yang senang dengan dirinya. 


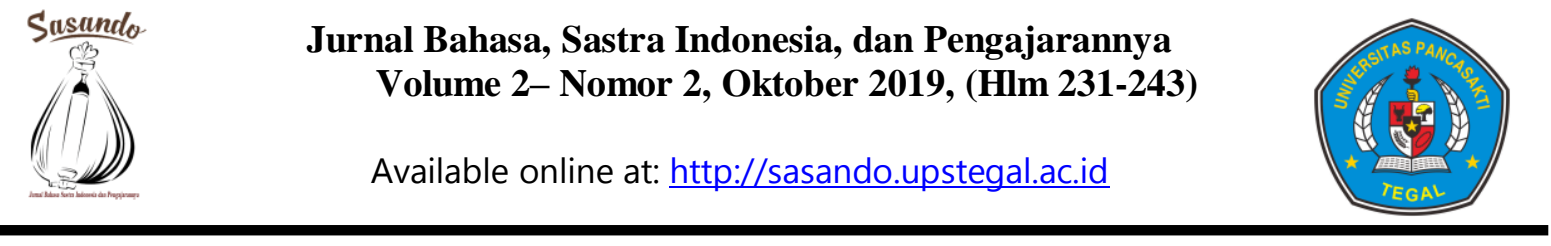

Nama Jenang Perkasa sebagai pemuda dan pedagang yang sukses serta sopan tersebar ke seluruh lapisan masyarakat pulau Bintan. Tak terkecuali juga ke telinga Batin Lagoi. Batin Lagoi ingin sekali berjumpa dengan pemuda tersebut. Dirinya penasaran, seperti apa sosok Jenang Perkasa pemuda yang menjadi pokok pembicaraan masyarakat itu.

Batin Lagoi khirnya mendapat ide untuk mendatangkan Jenang ke rumahnya. Batin Lagoi membuat acara selamatan di rumahnya. Undangan disebar ke seluruh masyarakat, tak terkecuali ke Jenang Perkasa, pemuda yang menjadi bahan pembicaraan masyarakatnya. Jenang Perkasa datang ke acara undangan selamatan Batin Lagoi.

Saat itulah, Batin Lagoi terkesima melihak sosok Jenang Perkasa. Seorang pemuda tampan, ramah, santun, dan sukses dalam melakukan perniagaan. Dalam diri Batin Lagoi bertanya-tanya anak siapa gerangan ini. Dimana rumahnya dan apa pekerjaannya.

Saat acara selamatan berlangsung, Batin Lagoi fokus memperhatikan prilaku Jenang Perkasa. Mulai dari tutur kata, sikap, hingga cara makan. Menurut pandangan batin Batin Lagoi, anak ini pasti bukan orang semba- rangan saja. Anak ini sepertinya anak seorang yang berbangsa. Oleh sebab itulah, Batin Lagoi sudah bertekat untuk mengambil pemuda ini dan menjadikan menantunya, yaitu menjadi suami Putri anaknya. Bila hal ini berhasil, tentunya kehidupan anaknya (Putri) akan berbahagia bersama suaminya.

Allah maha tahu dan menentukan segalanya. Setelah acar selamatan selesai, Batin Lagoi memanggil Jenang Perkasa untuk berbicara empat mata di ruang khusus. Di sinilah Batin Lagoi menyatakan niatnya untuk meminang Jenang Perkasa menjadi menantunya. Keinginan Batin lagoi ternyata mendapat sambutan baik Jenang perkasa. Jenang Perkasa memang sejak melihat Putri Pandan Berduri di rumah Batin Lagoi, hati kecilnya sudah berkata bahwa gadis cantik ini sangat cocok untuk dijadikan istrinya. Tal lama kemudian dilaksanakanlah pesta perkawinan antara Putri Pandan Berduri dengan Jenang Perkasa. Putri dan Jenang hidup rukun dan damai serta sejahtera. Buah perkwinan dari mereka adalah Putri melahirkan anak pertama, kedua, dan ketiga. Anak pertama bernama Batin Mantang. Anak kedua bernama Batin Mapoi. Anak ketiga bernama Batin Kelong. (dikutip dari: http://histori.id> $>$ legenda.putri-pandan-

beduri)

\section{Pembahasan}

a. Nilai Kearifan Lokal Legenda Putra Lokan

(a) Nilai Agama (Islam)

Dalam ajaran Islam disampaikan bahwa suami itu adalah khaliufah di rumah tangganya sendiri. Sebagai khalifah dirinya bertanggung jawab penuh terhadapo istri dan anak-anaknya. Baik tanggung jawab dalam memberikan nafkah maupun pendidikan mereka. Tanggung jawab suami terhadap istri adalah memberikan nafkah jasmani dan rohoni. Bila sudah tiga bulan suami tidak memeberikan nafkah (batin dan jasmani) maka istri berhak meminta cerai. Apalagi suami meninggalkan istri bertahun- tahun. Dalam ajaran Islam sang suami sudah berdosa terhadap istrinya. Sang Raja dalam hal ini jelas sudah melanggar nilai-nilai agama (Islam).

Tanggung jawab ayah kepada anakanaknya adalah memberikan makan, minum, pakaian, dan pendidikan yang cukup. Baik pendidikan agama maupun pendidikan umum 


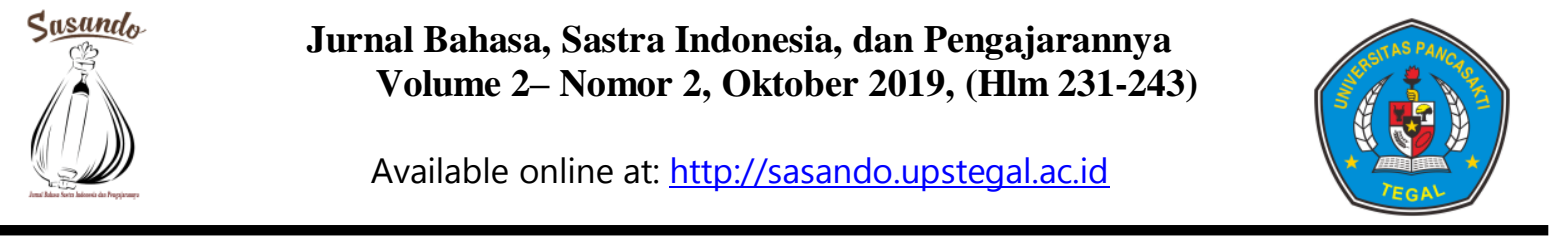

lainnya. Sang Raja dalam cerita ini jelas sudah melanggar ajaran Islam karena meninggalkan begitu lama anaknya di hutan. Dalam ajaran Islam, sang Raja jelas sudah berdosa kepada anak-anaknya.

\section{(b)Nilai Budi-Pekerti}

Adapun yang dimaksud dengan nilai budi pekerti adalah nilai berkaitan dengan prilaku atau moral. Tokoh Raja dalam legenda Putra Lokan ini jelas tidak memiliki prilaku atau moral baik. Suami seperti apa itu yang tega membuang istri dan anaknya ke tengah hutan hanya karena mendapat bisikan buruk dari pengawalnya. Dimana hati nurani sang Raja ini. Suatu prilaku suami yang tidak baik untuk dicontoh tentunya.

(3)Nilai SosialNilai sosial adalah nilai-nilai yang dijunjung tinggi dalam kehidupan masyarakat. Nilai social yang terkandung dalam legenda Putra Lokan ini adalah selalu ikhlas untuk memafkan orang lain. Tokoh yang memiliki prilaku seperti ini adalah istri sang raja dan anaknya yang bernama Putra Lokan. Dirinya rela memaafkan kesalahan yang telah dilakukan ayahnya selama ini. Hal ini dibuktikan dirinya rela mengusir para penghianat dari lingkungan istana. Ayahnya berhasil dilepaskan dari tawanan Datuk bendahara.

\section{(4) Nilai Kerja Keras}

Nilai kerja keras adalah nilai-nilai yang berkaitan usaha maksimal yang dilakukan seseorang dalam mencapai tujuannya. Tokoh yang memiliki nilai kerja keras di sini adalah tokoh istri dan Putra Lokan. Istri raja, dengan usaha kerja kerasnya dirinya berhasil membesarkan anaknya Putra Lokan. Dirinya berhasil mendidik Putra Lokan menjadi seorang anak yang berbakti kepada orangtuanya. Atas kerja keras yang telah dilakukannya, Putra Lokan berhasil memperoleh ilmu kedik- jayaan sehingga mampu mengalahkan para penghianat di kerajaan yang dipimpin ayahnya.

\section{(5) Nilai Pendidikan}

Nilai pendidikan yang sering juga disebut dengan nilai didaktis adalah nilainilai yang bersifat memberikan manfaat positif kepada orang lain. Nilai-nilai yang lebih ditekankan dari aspek ilmu pengetahuan dan dapat menjadi pedoman atau pelajaran. Nilai pendidikan yang terkandung dalam legenda Putra Lokan ini adalah jangan malu memiliki punya anak yang berkelainan. Bukankah anak itu merupakan ciptaan dan Titipan Allah. Membuang segala ciptaan Allah sama saja perbuatan menghina Allah. Ganjarannya pastilah Allah akan mendatangkan kemurkaan terhadapnya.

\section{b. Nilai Kearifan Lokal Legenda Putri Pandan Berduri}

(1) Nilai Agama (Islam)

Menurut ajaran Islam, anak itu adalah titipan atau amanah yang diberikan Allah kepada kita. Sebagai titipan Allah, maka kita wajib memegang teguh amanah tersebut dan men-jalankannya sebaik mungkin. Orangtua Putri Pandan Berduri yang sesungguhnya jelas tidak memegang amanah Allah dengan baik. Dengan teganya anaknya sendiri dibuang dan diletakkan di atas pandan berduri sendiri saja. Untunglah anak tersebut dijumpai oleh Batin Lagoi yang baik hati. Coba kalau seandainya dalam waktu yang lama anak itu ditinggal begitu saja, tentu akan meninggal karena kelaparan dan kehausan. 


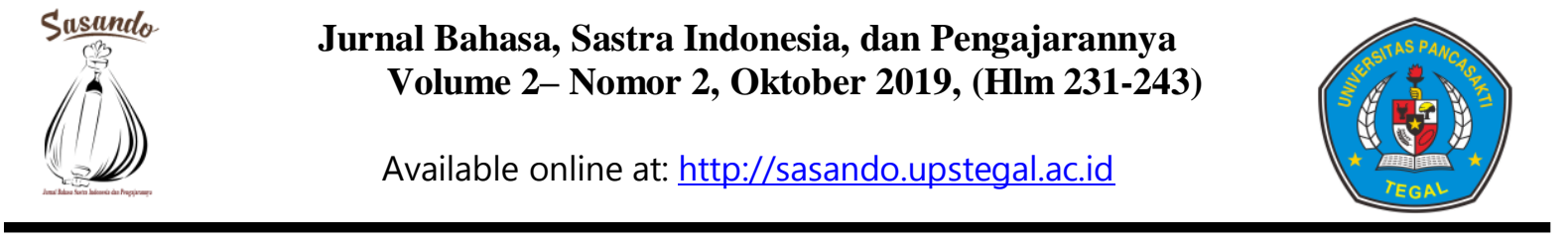

Tokoh Batin Lagoi telah mampu menjadi ayah angkat Putri pandan Berduri. Dirinya telah berjasa dalam membesarkan dan mendidik Putri hingga Batin Lagoi mampu mencarikan jodoh atau suami yang baik untuk anaknya tersebut. Jenang Perkasa juga telah mampu menjadi suami yang baik dan mendidik anak-anaknya dengan baik.

\section{(2) Nilai Budi-Peketi}

Nilai budi-pekerti adalah nilai-nilai yang berkaitan dengan prilaku atau nilai moral seseorang. Batin Lagoi merupakan sosok pemimpin yang memiliki budi-pekerti baik. Dirinya mampu memberikan contoh baik kepada masyarakatnya. Jenang Perkasa juga merupakan sosok anak yang penuh hormat kepada ayahnya. oleh sebab itu, dirinya tak mau bertengkar dengan kakaknya. Dirinya lebih memilih meninggalkan rumah dari pada membuat keributan di rumahnya.

(3)Nilai SosialNilai sosial adalah nilai-nilai yang dijunjung tinggi dalam kehidupan social atau bermasyarakat. Tokoh dalam legenda ini yang memiliki nilai social adalah (1) Batin Lagoi dan Jenang Perkasa. Batin Lagoi mampu berkomunikasi dengan masyaraktnya secara baik sehingga dirinya dipercaya sebagai pimpinan mereka (suku). Jenang Perkasa juga merupakan tokoh yang memiliki kemampuan sosial tinggi. Kehadirannya di tengah-tengah masyarakat Bintan sangat diterima. Cerita tidak ditemukan adanya penolakan masyarakat terhadap kehadiran Jenang Perkasa di tengah-tengah kehidupan mereka.

(4) Nilai Kerja Keras

Nilai kerja keras adalah nilai yang berkaitan dengan usaha untuk tidak berpangku tangan saja melainkan berusaha sekuat-kuatnya untuk memenuhi kebutuhan hidup sehari-hari. Tokoh dalam legenda Putri Pandan Berduri yang menunjukkan kerja kerasnya dalam berusaha atau memenuhi kebutuhan hidupnya sehingga berhasil menjadi orang kaya adalah Jenang Perkasa. Dengan meninggalkan Pulau Galang berlayar menuju Pulau Bintan tanpa membawa bekal yang banyak ternyata dirinya berhasil menjadi saudagar kaya di Pulau Bintan. Keberhasilan tersebut tidak lepas dari kerja keras dan ketekunan yang telah dilakukannya selama hidup di Bintan.

\section{(5) Nilai Pendidikan}

Nilai pendidikan yang dimaksud adalah nilai-nilai yang berasal dari ilmu pengetahuan yang mampu membawa manusia kearah yang lebih baik. Nilai pendidikan yang terkandung dalam legenda Putra Pandan Berduri ini adalah hormati orangtua, jangan bertengkar dengan saudara sendiri, jadilah orang yang baik budi-pekerti agar disayang oleh semua orang.

\section{SIMPULAN}

Berdasarkan hasil analisis data folklore, khususnya legenda Putra Lokan dan Putri Pandan Berduri maka dapat disimpulkan bahwa kedua legenda tersebut mengandung nilai-nilai kearifan lokal, seperti: (1) nilai agama, (2) nilai budipekerti, (3) nilai social, (4) nilai kerja keras, (5) nilai pendidikan. Dengan nilai kearifan local yang dimiliki kedua legenda tersebut maka kedua legenda tersebut tentunya sangat layak dijadikan sumber materi ajar di kelas.

\section{DAFTAR PUSTAKA}

Anton dan Marwati.2015. 'Ungkapan Tradisional Dalam Upacara Adat Perkawinan Masyarakat Bajo Di Pulau Balu Kabupaten Muna Barat" Sumber: ojs.uho.ac.id / index.php/ HUMANIKA 


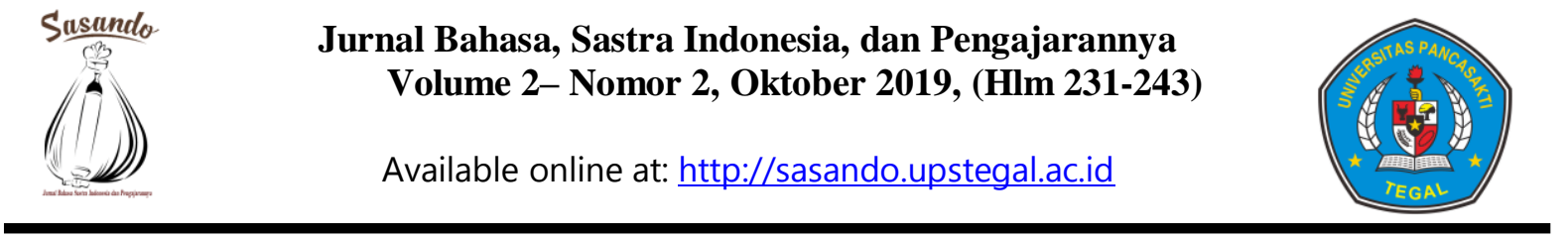

/article/download/123456/pd.25 Maret 201809.24

Angesti, Arjuna Jun Avithariyhana. 2013. "Tradisi Gapura Masjid Wali Di Desa Loram Kudus". Sumber:https://journal.unnes.ac.id/sj u/index.php/piwulang/article/downlo ad/ 2363/ 2169. 25 Maret 201809.29

Endraswara, Suwardi. 2011. Metodologi

Penelitian Sastra: Epistemologi, Model, Teori, dan Aplikasinya. Yogyakarta: CAPS -.2013. Folklore

Nusantara. Yokyakarta: Penerbit

Ombak

Ilminisa, Ranggi Ramadhani. dkk.2016."

Bentuk Karakter Anak Melalui

Dokumentasi Folklor Lisan

Kebudayaan Lokal". Sumber: https:// journal.um.ac. id /index.php/ jptpp/article/download/6353/2708 25 Maret 2018.09.12

Iskandar. 2008. Metodologi Penelitian Pendidikan dan Sosial: Kualitatif danKuantitatif). Jakarta:Gaung Persada Press

MPSS, Pudentia. 1998. Metodologi Kajian Tradisi Lisan. Jakarta: Yayasan Obor Indonesia dan Yayasan Asosiasi Tradisi Lisan

Nunung, Julaeha. 2016.

"Implementasi Nilai-Nilai

Kearifan Lokal masyarakat Rancakalong dalam Pembelajaran Sejarah”. Jurnal Metodik Didaktik. Volume 5, Nomor 25, Oktober 2016

Nursa'ah, Khotami. 2014. "Inventarisasi Cerita Rakyat Di Kabupaten Banjarnegara". Sumber: https : // journal.unnes.ac.id/sju/index.php /sutasoma/article/view4031/3657

Rachman, Doni, Pratiwi, Yuni, dan Roekhan. 2017. "Kajian Mitos Masyarakat Terhadap Folklor Ki Ageng Gribig". Sumber: jurnalonline.um.ac.id/data/.../artikel E3EBA269204A2171 BFA96 FD95DA8CB60.pdf

Sukmawan, Sony dan Nurmansyah, M. Andhy. 2012. "Etika Lingkungan Dalam Folklor Masyarakat Desa Tengger". Sumber: https://jurnal.unej.ac.id/index.php/LI T/article/ download/ 6081/4500

Sugono, Dendy. 2009. Tesaurus Alfabetis

Bahasa Indonesia. Jakarta: Balai Pustaka.

TIM. 2011. Kamus Bahasa Indonesia untuk Pelajar. Jakarta: Kemendikbudnas.

\section{Profil Singkat}

Drs. Suhardi, M.Pd., lahir 15 Agustus 1965 di desa Sei Nyalo Kecamatan Batangkapas Kabupaten Pesisir Selatan Kota Padang Sumatera Barat. Anak dari M. Yunin dan Rajia. Menikah dengan Nelvizar Chandra dan memiliki 4 anak, yaitu: Silvia Rahayu, Muhammad Ridho Ikram, Abel Ramzy Iestin, dan Hafiz Taufiqul Rahman. Lulus Sarjana (S.1) di FKIP Universitas Bung Hatta Padang tahun 1992. Selesai Program Magister Pendidikan Bahasa Indonesia tahun 2001 di Universitas Negeri Padang. Pernah menjadi dosen di IAIN Imam Bonjol Padang, Politeknik Batam, dan kini menjadi dosen di Universitas Maritim Raja Ali Haji (UMRAH) Tanjungpinang Indonesia. Selain mengajar, aktif di Lembaga Penelitian dan Pengabdian Kepada Masyarakat IAIN Imam Bonjol Padang, Pusat Kajian Islam Minangkabau Padang, Poltek Batam, dan kini aktif di LP3M UMRAH sejak tahun 2007. Sejak tahun 


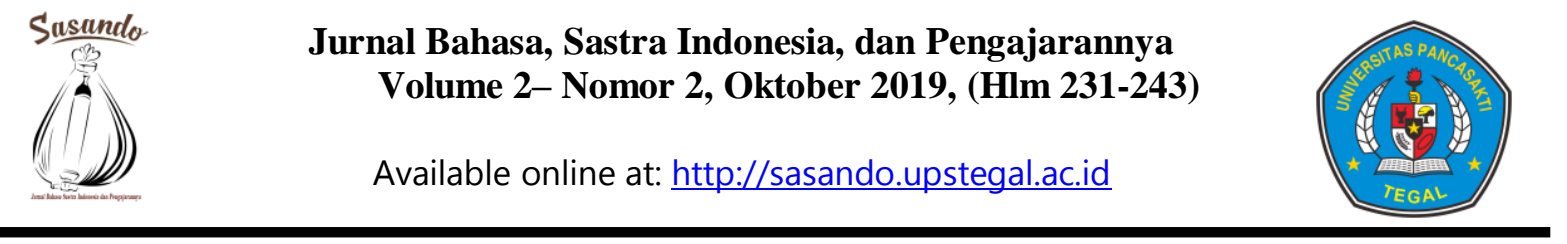

2003 aktif menulis artikel di media surat kabar, seperti: Padang Ekspres, Singgalang, Harian Haluan, Batam Pos, dan Haluan Kepri. Selain itu, sejak tahun 2011 aktif menulis buku. Buku pertama berjudul "Sastra Kita, Kritik dan Lokalitas", selanjutnya "Pengantar Linguistik Umum" (2013), Dasar-Dasar Ilmu Sintaksis (2013), dan "Dasar-Dasar Ilmu Semantik" (2015). Saat ini sedang mempersiapkan buku selanjutnya, yaitu "Folklore Masyarakata Melayu Kepulauan Riau". Direncanakan terbit akhir tahun ini. Selan itu juga aktif menulis artikel ilmiah di Jurnal Lingua Bahasa dan Sastra Indonesia UNNES dan Jurnal Pendidikan Bahasa dan Sastra UPI. 